\title{
ANP APPLIED TO ELECTRONICS ENGINEERING PROJECT SELECTION
}

\author{
Murad Habib, Member, IEEE * \\ Murad Habib is with University Of The Punjab, CEET, Quiad-i-Azam Campus, Lahore Pakistan, \\ +92-3008003560; e-mail: muradhabib@ hotmail.com \\ Javaid L. Piracha is a professor with the UET, LAHORE PAKISTAN
}

\begin{abstract}
Project selection in Electronics engineering is a complex decision-making process. This research paper illustrates an application of ANP/AHP process). The AHP (Analytic Hierarchy Process) is employed to break down large unstructured decision problems into manageable and measurable components. The ANP, as the general form of AHP, is powerful to deal with complex decisions where interdependence exists in a decision model. The research paper discusses the use of the ANP, a general form of Saaty's analytic Network process, as a model to evaluate the value of competing Electronics projects.

The research paper concludes with a case study describing the implementation of this model at an engineering college, including data based on the actual use of the decision making model. The case study helps to verify that AHP is an effective and efficient decision-making tool.

A major contribution of this work is to provide a methodology for assessing the best project. Despite a number of publications applying AHP in project selection, this is probably the first time that an attempt has been made to apply AHP in an electronics project selection in an engineering university environment.

Keywords-component; Analytic hierarchy process, analytic network process, multi criteria decisionmaking, Final year project selection.
\end{abstract}

\section{INTRODUCTION}

Project selection in Electronics Engineering field is a complex decision-making process. It involves a search of the environment of opportunities, the generation of project options, and the evaluation of multiple attributes, both qualitative and quantitative. Qualitative attributes are often accompanied by certain ambiguities because of the different perceptions of goals. Such differences in perceptions often hinder the attainment of compromise and coordination.

The Students with excellent technical skills must work within the limits of available funding and resources. FY project selection and funding decisions, then, are critical While there are many mathematical decisionmaking approaches proposed for this decision, literature suggests that few are actually being used. Major criticisms of these techniques include their inability to consider strategic factors and their mathematical complexity [1], [9], [16].

\footnotetext{
${ }^{*}$ Corresponding author
} 
University need tools that can help determine the best allocation of resources. This research paper discusses the application of the analytic hierarchy process (AHP), a multi attribute approach for decision making that allows for the transformation of qualitative values into quantitative values and performing analysis on them. The AHP is a relatively simple, sensitive approach that can be accepted by other decision-makers. The model presented in this research paper is an understandable approach utilizing both quantitative and qualitative assessments affecting to the decision of which alternative should be followed. The decision model is capable of taking into consideration multiple dimensions of information into the analysis, a powerful and necessary characteristic for any strategic evaluation. The research paper first reviews the nature of the FY (Final Year) project selection problem including its nature and needs. It discusses the various criteria on which the selection decision is made and how these criteria relate. After a brief review of AHP, a multi attribute selection framework represented as an ANP model is presented. A case example using data from an application of the model at an Electrical Engineering department is presented. The case study helps to verify that AHP is an effective and efficient decision-making tool. As a conclusion, the research paper discusses limitations and possible extensions to the model. The research paper concludes with a case study describing the implementation of this model at a College of Engineering and emerging technology in Punjab University Lahore, including data based on the actual use of the decision making model.

\subsubsection{Proposed model and approach}

\section{Case Study Company}

The model was developed and validated with the input of a College of Engineering and emerging technology, University Of The Punjab. PU is the old university, University newly establish the Electrical Engineering department. Department was trying to decide among final year projects proposals from the last years students. The options were to develop automatic meter reading, microprocessor trainer, and frequency jammer. For Final year project only one option could be pursued. Once a decision was made, the student was committed to pursuing that project.

The approach discussed in this research paper for the selection of FY projects has been tested for Pakistani university environments.

The uncertainty and risk associated with the success of a FY project creates the problem that the company may be helpless or even worse off if the selection of the project is an implementation failure. Here, the whole problem of FY project selection has been analysed and the interrelationships among the different factors have been taken into account. In this research paper, options are evaluated on hierarchical levels: (i) goal (ii) Project Phases (iii) the decision-making criteria (iv) three options; project selection is described in figure 1, which shows a three level hierarchy for the various criteria relevant to project selection. The goal is placed at the top of the hierarchy and is afterward maintained in accordance with the priority. Different levels of the hierarchy are illustrated in the following subsections.

\subsubsection{Decision Model Development}

The first step is to construct a model to be evaluated. This example uses the factors to develop a model that openly considers many of the R\&D selection issues found in literature and practice. The model is summarized in Fig. 1. The relevant criteria and alternatives are structured in the form of a hierarchy. More "strategic" decisions are shown higher in the hierarchy. The model development requires the development of attributes at each level and all may have some degree of interdependence with the three basic phases of research, "basic, and development". The other single arrows indicate a one-way relationship. The topmost or overall goal is to pick the best project. We are seeking to determine which of several 
alternatives (shown at the bottom of the hierarchy) would best support the realization of this goal. Since we cannot directly assess the alternatives versus the goal, the intermediate levels of the hierarchy are developed.

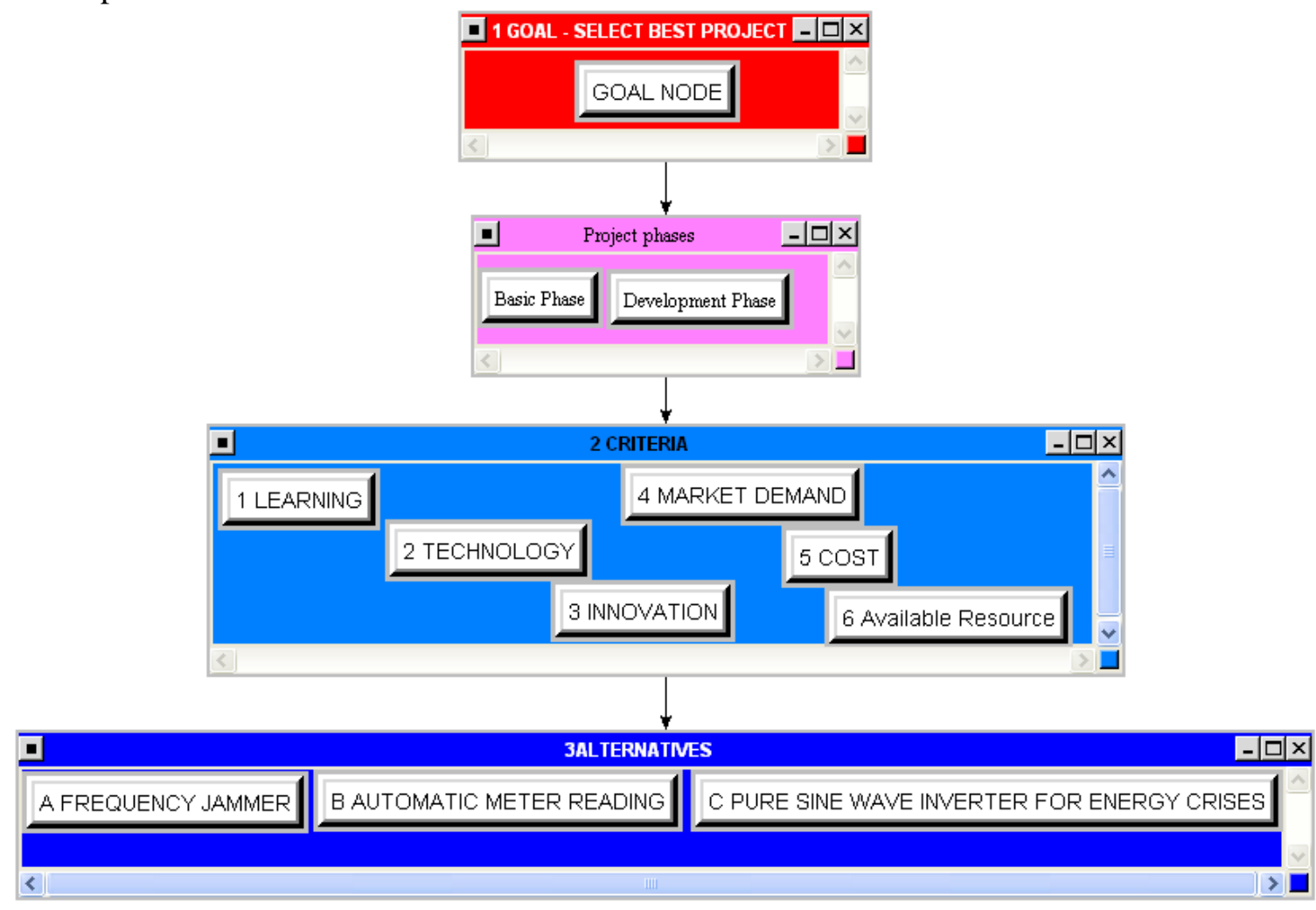

Figure 1. Analytic Hierarchical framework showing the various attributes of project selection

\subsection{Different phases of an $R \& D$ project}

Any project can be divided into two phases: basic, and development. The importance of various attributes and criteria varies with the phase in the project life. For example, technological and general attributes are of more importance in the basic phase, whereas market attributes are of more importance in the development phase. The main objective behind the area of this level is to estimate the various decision criteria separately for different phases and to integrate the various preconceptions of the stakeholders. The basic activities of the two phases are illustrated as follows.

\subsubsection{Basic phase.}

In this phase, knowledge concerning the technology is collected. To get technical and marketing assistance in the future, the new product to be developed is associated with previous products. In this phase, different surveys are made and all the resources necessary for the research are collected. The research may concern some technology with the aim of improving an existing product or process or may be investigated with the possibility of leading to new products or processes. Often, the research is conducted simply for the sake of understanding a particular technology.

3.1.2 Development phase. 
This is the final phase of an $R \& D$ project. The technology developed in the applied phase is used for the development of the new product. In this phase, design, quality, and procurement issues related to product manufacture are considered.

\subsection{DIFFERENT FACTORS AFFECTING DECISION-MAKING}

Decision-making is affected by following factors, technology, innovation, market demand of project, cost, learning, and available resource.

3.2.1 Technical attributes. These attributes related to the project itself and the technology being investigated. Specific measures include: probability of technical success; existence of project champion; existence of required competence; availability of available resources (Resource); applicability to other products and processes; time to market.

John H. Friar suggests that there are three major groups of appropriate variables for successful new product innovation and $R \& D$ projects:

- Nature of the innovation; • Nature of the market; - Nature of the technology.

\subsubsection{NATURE OF THE INNOVATION}

We will consider two levels of innovation - incremental and radical. An incremental innovation is one where the basic technology and product configuration remains essentially the same and only minor modifications are made to the performance, flexibility, appearance, and other characteristics. The incremental innovation is usually attempted in a well-established market. A radical innovation is one where the technology is considerably different from the earlier product. In the case of radical innovation, the market may not exist at all. The product design in such cases may be based solely on the creative natures of the designer by understanding user needs through understanding with the user world.

The nature of the innovation has different effects on market and organization factors affecting the success of the new product or $R \& D$ project. In the case of a radical innovation it is much harder, if not impossible, to forecast and perform early analyses on customer needs, market size, market growth, and competition. Consequently, using formal market analysis is relatively less important. On the other hand, an incremental innovation requires a thorough market analysis of an existing market.

\subsubsection{Nature of the Market}

The nature of the market for a new product can be categorized into two types - existing and new. Whether a company is innovating in an existing market or trying to create a completely new market will cause differences in factors. In the former case, the new product meets an existing need but with some improvements, and therefore the market uncertainty is relatively low. The market analyses for the two types are completely different. Likewise, the quality of the information one can discover about the market and customers will differ so that the meaning of some factors will change.

\subsubsection{NATURE OF THE TECHNOLOGY}

Although classifying technology is hard, one useful classification is high tech versus low tech. The uncertainties in market and technology are different for the two groups. Link found differences in factors depending on whether the setting was high tech. In the high-tech field, the technology is developing very rapidly, and so new product introductions come quickly. The applications and customers may not yet be determined if the technologies are still emerging. 


\subsubsection{Costs}

Under Economic costs, there are three clusters: Financial, Operational, and Resources These clusters include the following nodes.

Financial nodes: Cost of Electronics parts, Personnel, and Legal. Assets refer to the cost of retaining IT infrastructure for things such as R\&D equipments.

- Operational nodes: Time to finish project, Use of project management, Knowledge transfer during requirements definition, Control/influence over human resources, and Fast time-to-market. In terms of cost, the first four items' cost increases with transfer technology. They are interrelated with or without transfer technology.

- Resources nodes: Knowledge of latest technologies and availability. Without transfer technology, these two items become costs; resources with knowledge of the latest technologies may not be available quickly.

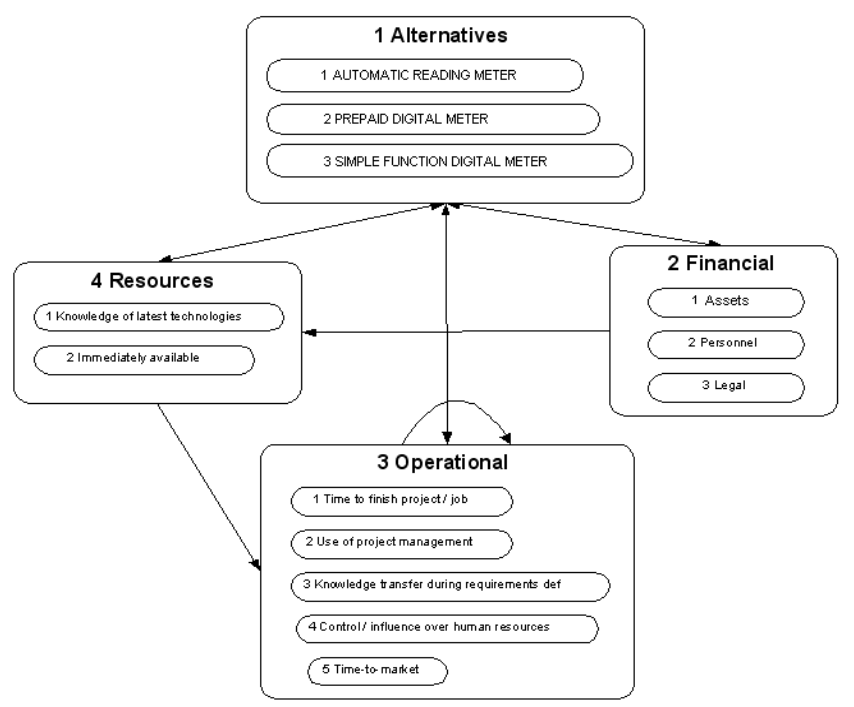

Figure A. Clusters with elements under Economic Costs

\subsection{Pair wise Comparis ons}

Extracting favorite of various components and factors requires a series of pair wise comparisons where the decision maker will compare two components at a time with respect to an upper level "control" criterion. In AHP, pair wise comparisons of the elements in each level are conducted with respect to their relative importance toward their control criterion. Saaty [22] has suggested a scale of 1 to 9 when comparing two components, with a score of 1 representing indifference between the two components and 9 being overpowering authority of the component under consideration (row component in the matrix) over the comparison component (column component in the matrix). In our example, if a component has some level of weaker impact the range of scores will be from 1 to 1/9, where 1 represents indifference and 1/9 being an overpowering authority by a column element over the row element. When a judgment is assigned to a pair in the $(\mathrm{i}, \mathrm{j})$ position, the reciprocal value is automatically assigned in the $(\mathrm{j}, \mathrm{i})$ position.

\begin{tabular}{|c|c|c|c|c|}
\hline Basic & Tech & Mktg & Org & eVector \\
\hline Technical & 1 & 2 & 6 & 0.23 \\
\hline Market & 5 & 1 & 7 & 0.708 \\
\hline Organizational & 0.167 & 0.143 & 1 & 0.062 \\
\hline & & & & 1 \\
\hline
\end{tabular}


That is, if $a_{i j j}$ is a matrix value assigned to the relationship of component $\mathrm{i}$ to component $\mathrm{j}$, then $a_{j i}$ is equal to $1 / a_{i, j}$ (or $a_{j i}=1$ ). Since many of these values are strategic, additional strategic group decision-making tools such as scenario planning or the Delphi approach can be utilized to assign meaningful values to these pair wise comparisons. Once the pair wise comparisons are completed, the local priority vector $\mathrm{W}$ (defined as the eVector in the example figures) is computed as the unique solution

$$
\boldsymbol{A w}=\lambda_{\max } \boldsymbol{w}
$$

to

Where $\lambda_{\max }$ is the largest Eigenvalue of the matrix $\boldsymbol{A}$. Saaty provides several algorithms for approximating $w$. In this research paper, a two stage algorithm that involved forming a new $\mathbf{n} \times \mathbf{n}$ matrix by dividing each element in a column by the sum of the column elements and then summing the elements in each row of the resultant matrix and dividing by the $\mathbf{n}$ elements in the row. This is referred to as the process of averaging over normalized columns. This is represented as

$$
w_{i}=\frac{\sum_{i=1}^{I}\left(\frac{a_{i j}}{\sum_{j=1}^{J} a_{i j}}\right)}{J}
$$

Where

Wi weighted priority for component;

J index number of columns (components);

I index number of rows (components).

In the assessment process, inconsistencies may occur. For an explanation of inconsistency in a matrix of pair wise comparisons and how to calculate it, see Saaty[22]. 
TABLE II

BASIC STAGE OF RESEARCH PAIRWISE COMPARISON MATRIX FOR ACTORS AND EIGENVECTOR (RELATIVE IMPORTANCE/IMPACT WEIGHTS)

\begin{tabular}{l|ccc||c}
\hline Basic & Mgt & Marketing & Tech & eVector \\
\hline Management & 1.000 & 0.143 & 0.125 & 0.054 \\
Marketing & 7.000 & 1.000 & 0.167 & 0.213 \\
Technologist & 8.000 & 6.000 & 1.000 & 0.734 \\
\hline \multicolumn{5}{l}{} \\
\hline
\end{tabular}

TABL.E III

INITIAL SUPFRMATRIX $M$ COMPILED FrOM MATRICES $A$ AND $B$ FOR STAGE OF RESEARCH AND ACTOR LINKAGES

\begin{tabular}{l|cccccc}
\hline & Basic & Applied & Develop & Mgt & Mrkt & Tech \\
\hline Mgt & 0.054 & 0.066 & 0.065 & 0 & 0 & 0 \\
Mrkt & 0.213 & 0.735 & 0.734 & 0 & 0 & 0 \\
Tech & 0.734 & 0.199 & 0.201 & 0 & 0 & 0 \\
Basic & 0 & 0 & 0 & 0.062 & 0.055 & 0.650 \\
Applied & 0 & 0 & 0 & 0.353 & 0.188 & 0.287 \\
Develop & 0 & 0 & 0 & 0.585 & 0.757 & 0.063 \\
\hline
\end{tabular}

TABLE IV

SuPERMATRIX CONVERGENCE TO "LONG TERM" WEIGHTS AT M 31

\begin{tabular}{l|cccccc}
\hline & Basic & Applied & Develop & Mgt & Mrkt & Tech \\
\hline Mgt & 0.065 & 0.065 & 0.065 & 0 & 0 & 0 \\
Mrkt & 0.700 & 0.700 & 0.700 & 0 & 0 & 0 \\
Tech & 0.235 & 0.235 & 0.235 & 0 & 0 & 0 \\
Basic & 0 & 0 & 0 & 0.305 & 0.305 & 0.305 \\
Applied & 0 & 0 & 0 & 0.279 & 0.279 & 0.279 \\
Develop & 0 & 0 & 0 & 0.416 & 0.416 & 0.416 \\
\hline
\end{tabular}

When one uses the simplified algorithm mentioned above to compute the priority vector there is no calculation of the inconsistency. An example of the pair wise comparison matrix within the Basic stage of research is shown in Table I. The weightings are obtained from the decision maker by asking a series of comparison questions. For this matrix in Table I, the decision maker was asked questions such as: "During the Basic stage of research, which element is more important: Technical or Marketing?"

Marketing is considered to be 5 times more important than technical and a judgment of 5 is entered in the cell at the intersection of the Marketing row and Tech column. Technical is the row component and Marketing is the column component. The reciprocal judgment of 0.200 (1/5) is entered in the (Tech, Marketing) cell. The pair wise comparison approach is used to populate the matrix with the diagonal elements being 1 , that is, an element is equally preferred to itself. The priorities for this matrix are shown as the last column in Table I (labeled eVector). In this stage of research, the Marketing category received the highest rating (0.708). In this company, even at early stages of research, marketing factors are the most important in determining whether a project proceeds or not (probably not an unusual or unreasonable situation).

\subsection{Analyze Measures}

In this illustration, no interdependence between the actors and the measures is assumed to exist. Similar pair wise comparisons to those made earlier are conducted for the measures relative to the actor to determine their relative importance weight calculation (or eigenvector determination). There are three separate pair wise comparison matrices (technical, market, and organizational) that have to be developed for this step in the analysis. Table V shows one of those matrices. In this case, the performance of the alternatives on each of the technical metrics is established through pair wise comparing the alternatives against each other with respect to that metric, for example "Potential market size" as shown in the figure below. The resulting vector shows the priorities of the alternatives on that metric. The alternative with the largest priority is perceived to be best on the metric. The synthesis of the results across all the metrics gives the best overall alternative. For the company in question, all of the metrics with the exception of the 
presence of a project champion were found to be fairly close to each other in importance. The lack of significance for the Project Champion can probably be attributed to the small size of the company.

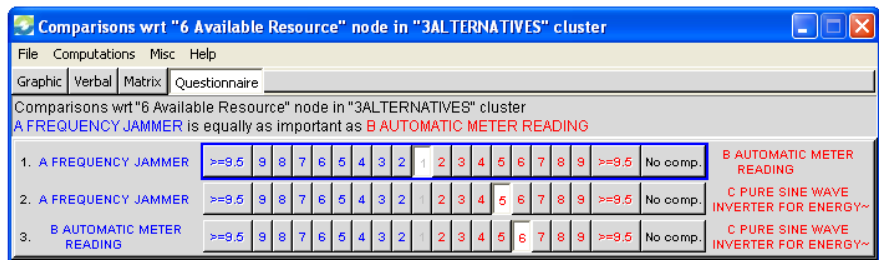

Observation and Results

\subsection{Synthesis - Getting the Results}

The results for the alternatives are obtained with the Synthesis command in the Main Model View. Select the Computations/Synthesize command, or click the shortcut icon Sym to see the final results:

\subsection{ReSUlTS FROM THE SYNTHES IS COMMAND}

The Normal column presents the results in the form of priorities. This is the usual way to report on results. The Ideals column is obtained from the Normal column by dividing each of its entries by the largest value in the column. The Raw column is read directly from the Limit Super matrix. In a hierarchical model such as this one the Raw column and the Normal column are the same.

\begin{tabular}{|c|c|c|c|c|}
\hline \multicolumn{5}{|c|}{$\begin{array}{l}\text { Here are the overall synthesized priorities for the } \\
\text { alternatives. You synthesized from the network Super } \\
\text { Decisions Main Window: Final Year Project } \\
\text { Selection.mod }\end{array}$} \\
\hline Name & Graphi & Ideals & Normals & Raw \\
\hline A FREQUENCY JAMMER & & 0.189746 & 0.130836 & 0.043612 \\
\hline 3 ALTOMATIC METER READING & & 0.260513 & 0.179632 & 0.059877 \\
\hline $\begin{array}{l}\text { PURE SINE WANE INWERTER } \\
\text { FOR ENERGY CRISES }\end{array}$ & & 1.000000 & $\mid 0.689532$ & 0.229844 \\
\hline
\end{tabular}

\subsection{OBSERVATION}

These results show that the Automatic meter reading the best choice for this decision maker. The "Ideal" column shows the results divided by the largest value so that the best choice has a priority of 1.0. The others are in the same proportion as in "Normal" and are interpreted this way: The Pure Sine wave is best (1.000), the Automatic is $17.9 \%$ as good, and the Jammer is $13.0 \%$ as good.

6 Conclusions

The purpose of this research paper was to present a method for project selection that allows for the consideration of important interactions among decision levels and criteria. The methodology uses the AHP for this evaluation. A model of the FY project selection process developed from literature and adapted for a University was presented. The research paper provides value to practitioners by providing a standard model for project selection and to researchers by demonstrating a new application of AHP. This strategic decision making tool assisted the company in comparing the projects and their selection. The model suggested the development of Pure Sine wave inverter, which is the option that the student pursue. The case study helps to verify that AHP is an effective and efficient decision-making tool. In fact, this is one 
of the strengths of AHP and ANP: the ability to adapt a basic framework to a particular situation. A decision criterion that a company considers crucial can easily be added to the generic model. In addition, the weighting given each component in the model is dependent on the decision maker(s) evaluating the component. For example, an project stressing competitive advantage through innovation would likely end up with criteria and weighting different from an enterprise seeking to compete as a low cost provider of proven technology. Despite a number of publications applying AHP in project selection, this is probably the first time that an attempt has been made to apply in Final Year project selection.

This research paper presents an effective method for performing FY project selection based on the attributes and criteria that serve the purpose of the company. The case study provides an example of the application of the methodology to a real-life situation. The methodology presents a more accurate mode for extracting the preferences of decision makers. The major contributions of this research are as follows. First, an ANP framework for Final Year project selection has been proposed with the goal of extending the current literature in the field. The framework includes a group-based modeling method that facilitates the FY project selection process, and a corresponding ANP architecture that supports and coordinates the work of decision-making groups. Second, this research paper presents an application of the proposed framework to a real project selection system. In conclusion, this model provides a qualitative and quantitative assessment of the attributes of a project surrounding the nonlinear relationships among interdependent levels. A major contribution of this work is to provide a methodology for assessing the best project. Also author introduce first time innovation factor in the AHP model. The company and decisionmaker involved in the case study were generally pleased with the approach.

After pair-wise comparisons of the alternatives and ratings comparisons of the merits, our model shows that Alternative \#1: "Pure Sine Wave Inverter," is the best choice. The main driver for this result is the financial benefits. Using background research and personal interviews to describe this model and compare and rate its nodes, we are not surprised by this outcome.

Table 'A' overall Outcome

Alternative Rankings
\begin{tabular}{|c|c|c|c|c|c|c|}
\hline Graphic & Alternatives & Total & Nornal & Ideal & Ranking \\
\hline & A FREQUENCY JAMMER & 0.0436 & 0.1308 & 0.1897 & 3 \\
\hline & B AUTOMATIC METER READING & 0.0599 & 0.1796 & 0.2605 & 2 \\
\hline
\end{tabular}

\section{REFERENCES}

[1] A. Albala, "Stage approach for the evaluation and selection of R\&D projects," IEEE Trans. Eng. Manage., vol. 22, pp. 153-164, 1975.

[2] A. Alidi, "Use of the analytic hierarchy process to measure the initial viability of industrial projects," Int. J. Project Manage., vol. 14, no. 4,pp. 205-208, 1996.

[3] K. M. A. -S. Al-Jarbi, "Application of the AHP in project management," Int. J. Project Manage., vol. 19, pp. 19-27, 2001.

[4] N. Baker and J. Freeland, "Recent advances in R\&D benefit measurement and project selection methods," Manage. Sci., vol. 21, no. 10, pp. 1164-1175, 1975.

[5] R. F. Bordley, "Keeping it sophisticatedly simple in R\&D selection," Eng. Econ., vol. 44, no. 2, pp. 168-183, 1999.

[6] M. S. Brenner, "Practical R\&D project prioritization,” Res. Technol. Manage., vol. 27, no. 5, pp. 3842, 1994.

[7] R. G. Cooper, "Doing it right," Ivey Bus. J., vol. 64, no. 6, pp. 54-60, 2000.

[8] N. Danila, "Strategic evaluation and selection of R\&D projects," R\&D

Manage., vol. 19, no. 1, pp. 47-62, 1989. 
[9] P. Fahrni and M. Spatig, "An application oriented guide to R\&D selection and evaluation methods," R\&D Manage., vol. 20, no. 2, pp. 155-171, 1990.

[10] P. Harker and L. Vargas, "The theory of ratio scale estimation: Saaty's analytic hierarchy process," Management Science, vol. 33, no. 11, pp. 1383-1403, 1987.

[11] A. D. Henriksen and A. J. Traynor, “A practical R\&D project-selection scoring model," IEEE Trans. Eng. Manage., vol. 46, pp. 158-170, May 1999.

[12] J. W. Lee and S. H. Kim, "Using analytic network process and goal programming for interdependent information system project selection," Comput. Oper. Res., vol. 27, no. 2000, pp. 367-382, 2000.

[13] , "An integrated approach for independent information systems project selection," Int. J. Project Manage., vol. 19, no. 2, pp. 111-118, 2001.

[14] M. Liberatore and G. Titus, "The practice of management science in R\&D project selection," Manage. Sci, vol. 29, no. 8, pp. 962-974, 1983.

[15] M. J. Liberatore, "An extension of the analytic hierarchy process for industrial R\&D project selection and resource allocation,” IEEE Trans. Eng. Manage., vol. 34, pp. 12-18, Feb. 1987.

[16] G. Lockett, B. Hetherington, and P. Yallup, "Modeling a research portfolio using AHP: A group decision process," R\&D Manage., vol. 16, no. 2, pp. 151-160, 1986.

[17] J. P. Martino, R\&D Project Selection. Pre Paid meter: Wiley, 1995. [18] L. M. Meade and J. Sarkis, "Analyzing organizational project alternatives for agile manufacturing processes: An analytical network approach,” Int. J. Prod. Res., vol. 37, no. 2, pp. 241-261, 1999.

[19] A. Presley and D. Liles, "R\&D validation planning: A methodology to link technical validations to benefits measurement," R\&D Manage., vol. 29, no. 4, pp. 55-65, 2000.

[20] J. L. Ringuest, S. B. Graves, and R. H. Case, "Conditional stochastic dominance in R\&D portfolio selection,” IEEE Trans. Eng. Manage., vol. 47, pp. 478-484, Nov. 2000.

[21] T. Saaty, "Priority setting in complex problems," IEEE Trans. Eng. Manage., vol. 30, pp. 140-155, 1983.

[22] , Multicriteria Decision Making: The Analytic Hierarchy Process. Pittsburgh, PA: Univ. of Pittsburgh Press, 1988. 